\title{
Influence of Ambiguity on Success of Public Infrastructural Megaprojects in Kenya
}

\author{
Austin Baraza Omonyo ${ }^{1}$, Prof. Roselyn Gakure ${ }^{2}$, Prof. Romanus Odhiambo ${ }^{3}$ \\ ${ }^{1}$ Centre for Finance \& Project Management ${ }^{\mathrm{TM}}$ \\ College House, 2nd Floor, Koinange Street, Nairobi, Kenya \\ ${ }^{2}$ Jomo Kenyatta University of Agriculture and Technology \\ School of Entrepreneurship \& Management, Main Campus, Thika, Kenya \\ ${ }^{3}$ Jomo Kenyatta University of Agriculture \& Technology \\ Office of The Deputy Vice Chancellor, Academics, Main Campus, Thika, Kenya
}

\begin{abstract}
The objective of this study was to investigate the influence of ambiguity on success of public infrastructural megaprojects in Kenya. The need for this study arose from the thesis that ambiguity is a key cause of complexity that results in infrastructural megaprojects being delivered over budget, behind schedule, with benefit shortfalls, over and over again. The study was designed as multiple-method research based on virtual constructionist ontology recognizing that complexity is the mid-point between order and disorder. A crosssectional census survey of completed public infrastructural megaprojects was conducted using two interlinked questionnaires. Quantitative data was analyzed using descriptive and inferential statistics while qualitative data was analyzed using expert judgment, scenario mapping and retrospective sense-making. The projects surveyed majorly utilized fixed price contracts with the outcome of increased delivery within budget than within schedule. The results showed that ambiguity had significant negative influence on process and overall success of public infrastructural megaprojects but had no significant relationship with product and organizational success. Projects in which the client assumed responsibility for cost and schedule risk had higher chances of meeting both cost and schedule objectives. In order to manage the negative effects of ambiguity, we recommend a new perspective to contract design of public infrastructural megaprojects based on complexity science, blending both outcome and behavior-based contracts. Such contracts should ensure that, in the face of ambiguity, the contractors are able to act in the best interest of their clients and that the clients have access to quality Project Management Information Systems.
\end{abstract}

Keywords: Ambiguity, megaproject, complexity, project success

\section{Introduction}

Public infrastructural megaprojects are large-scale, complex ventures that cost billions of money, take many years to develop and build, involve multiple public and private stakeholders, are transformational, and impact millions of people (Flyvbjerg, 2014). These projects are generally "greenfield" in nature as they often create new assets and utilize a variety of delivery models depending on their inherent complexity. They are often trait-making since they are designed to change the structure of society. This is in contrast with smaller and more conventional projects that are trait taking, often fitting into pre- existing structures without modification (Hirschman, 1995). Brady and Davies (2014) note that megaprojects are among the most complex category of project.

In Kenya, the growth in the use of infrastructural megaprojects to deliver goods and services has been phenomenal over the past few years and there appears to be no end in sight for their use. This is despite the fact that megaprojects are always delivered over budget, with schedule delays, with benefit shortfalls, over and over again (Flyvbjerg, 2014). The complexity inherent in the megaproject environment is often cited as the main cause of this poor performance (Cooke-Davies, 
Crawford \& Stephens, 2011). Without a coherent research agenda to understand both its causes and navigation strategies, complexity continues to result in problems, waste and socio-economic failure (Remington \& Zolin, 2011). As a step in taking this agenda forward, and building on the work of earlier researchers such as Maylor, Vidgen and Carver (2008), the Project Management Institute (PMI) published a Practice Guide on Navigating Complexity in 2014. This Guide describes the causes of complexity in three categories namely; human behavior, ambiguity and system behavior.

Whereas a number of studies have been conducted to explain the centrality of complexity in determining success of infrastructural megaprojects, most of these studies conclude that human behavior is the main cause of poor performance in these projects (Collyer, 2016; Olaniran, Love, Edwards, Olatunji \& Mathews, 2015; Meyer, 2014; Shore, 2008; Flyvbjerg, Holm \& Buhl, 2004; Lovallo \& Kahneman, 2003; Bruzelius, Flyvbjerg \& Rothengatter, 2002; Mackie \& Preston, 1998; Kahneman \& Tversky, 1979). This is despite existence of the thesis that there is a significant positive relationship between ambiguity and both customer and organizational outcomes (Hargen \& Park, 2013). Ambiguity arises from unclear or misleading events, cause and effect confusion, emergent issues or situations open to more than one interpretation in programs and projects (PMI, 2014). As a result of this ambiguity, the whole is always greater than the sum of the parts leading to uncertainty in performance of the project metrics. As Brady and Davis (2014) demonstrate, handling this inherent ambiguity to ensure stability can indeed enhance success of megaprojects. Once stability is achieved, the project schedule is able to absorb emerging disruption arising from dependencies and connections among its component parts thus ensuring that the dynamics of the system as a whole are kept under control. It is argued that achieving stability is as important as the more common measures of project performance (Swartz, 2008). It is on the basis of this proposition that this multiple-method research based on virtual constructionist ontology was designed. The study surveyed managers, team members, sponsors and key stakeholders of completed public infrastructural megaprojects to investigate the influence of ambiguity on success of public infrastructural megaprojects with a view to making recommendations on how to manage its effects. Ambiguity was operationalized through its components namely; context, emergence and uncertainty (PMI, 2014). The results of the study showed that each of these components of ambiguity were related to success and that the overall ambiguity had significant negative influence on success of public infrastructural megaprojects.

The remainder of this article is organized as follows: the relevant theoretical and empirical literature are reviewed leading to the formulation of the study hypothesis and a presentation of the conceptual framework. The next section describes the methodology followed by the study and this is followed by a section on results of the study and a discussion of those results. The last section presents the conclusions and references.

\section{Theoretical and Conceptual Framework}

\subsection{Theoretical Framework}

This study was operationalized through two theories namely; Complex Adaptive Systems and Project Success theories. Each of these theories is briefly discusses below:

\subsubsection{Complex Adaptive Systems Theory}

Complex Adaptive Systems (CAS) theory also referred to as Complexity theory, states that critically interacting components self-organize to form potentially evolving structures exhibiting a hierarchy of emergent system properties (Lucas, 2009). The rise of CAS as a school of thought is usually attributed to the mid-1980's formation of the Santa Fe Institute, a New Mexico think tank formed in part by the former members of the nearby Los Alamos National Laboratory. The scientists here claimed that through the study of complexity theory, one can see both laws of chaos and that of order; through which an explanation for how any collection of components will organize itself can be generated (Waldrop, 1992).

Complexity theory is concerned with the study of how order, structure, pattern, and novelty arise from extremely complicated, apparently chaotic systems and conversely, how complex behavior and structure emerges from simple underlying rules. The theory attempts to discover how the many disparate elements of a system work with each other to shape the system and its outcomes, as well as how each component changes over time (PMI, 2014). Insights from the study of complexity in the life sciences suggests that there is a natural tendency for all organisms (including human kind and social organisms such as project teams) to evolve complex responses to challenges that they encounter in their environment. 
Another important concept in complexity theory is that there is no master controller of any system. Rather, coherent system behavior is generated by the competition and cooperation between actors that is always present. The components of a system have different levels of organization-made up of divisions, which contain different departments, which in turn comprise different workers. But the important differentiation from this organization is that complex adaptive systems are constantly revising and rearranging their building blocks as they gain experience (Caldart \& Joan, 2004).

The CAS theory is reinforced by the Chaos theory which studies the behavior of dynamical systems that are highly sensitive to initial conditions. The theory is attributed to Edward Lorenz who while using a computer to simulate weather systems in 1960 at Massachusetts Institute of Technology, discovered one important aspect of how non-linearity affects the weather-the principle of sensitive dependence on initial conditions (Lorenz, 1963). Lorenz's discovery of how minute changes can have major and unpredictable consequences in nonlinear systems became known as the "butterfly effect". According to this theory, small differences in initial conditions yield widely diverging outcomes for such dynamical systems, rendering long-term prediction impossible in general (Kellert, 1993). Thus, a small initial schedule delay in delivering one component of a megaproject can lead to more than proportionate delay in the entire project.

The CAS and Chaos theory are helpful in defining the main aspects of ambiguity namely; context, emergence and uncertainty. Emergence is an unanticipated change, spontaneous or gradual, that occurs within the context of a program or project. Uncertainty is a state of imperfect knowledge about future occurrences on the project while context is the environmental set-up within which the project is implemented.

\subsubsection{Project Success Theory}

There have been various attempts over the history of project management to define suitable criteria against which to anchor and measure project success (McLeod, Doolin \& MacDonell, 2012). The most recognized of these measures is the long established and widely used "iron triangle" of time, cost and quality (Atkinson, 1999; Cooke-Davies, 2002; de Wit, 1988, Ika, 2009; Jugdev, Thomas, \& Delisle, 2001). However, the "iron triangle" dimensions are inherently limited in scope
(Atkinson, 1999; Ika, 2009; Wateridge, 1998). A project that satisfies these criteria may still be considered a failure; conversely a project that does not satisfy them may be considered successful (Baccarini, 1999; de Wit, 1988, Ika, 2009). The "iron triangle" only focuses on the project management process and does not incorporate the views and objectives of all stakeholders (Atkinson, 1999; Baccarini, 1999; Bannerman, 2008; de Wit, 1988; Jugdev \& Muller, 2005; Wateridge, 1998).

Researchers have progressively widened the scope and constituency of what is meant by project success, recognizing that project success is more than project management success and that it needs to be measured against overall objectives of the project thus reflecting a distinction between the success of a project's process and that of its product (Baccarini, 1999; Markus \& Mao, 2004; Wateridge, 1998). Product success involves such criteria as product use, client satisfaction and client benefits (McLeod et al., 2012).

Researchers are also increasingly advocating for project success criteria that incorporates achievement of broader set of organizational objectives involving benefits to the wider stakeholder base (see Shenhar, Dvir, \& Levy, 1997; Shenhar, Dvir, Levy \& Maltz, 2001; Shenhar \& Dvir, 2007; Hoegl \& Gemuenden, 2001). This is plausible given that projects are a means of delivering the organization's strategic objectives. Proponents of this school of thought advocate for inclusion of success criteria such as business and strategic benefits. It is this broader context of success that appeals to infrastructural megaprojects.

\subsection{Conceptual Framework}

Even though there are no studies that have directly assessed the influence of ambiguity on success of public infrastructural megaprojects, studies have been done that show the importance and usefulness of ambiguity in explaining project outcomes. For instance, in a study on managing structural and dynamic complexity, Brady and Davis (2014) used a comparative study of two successful megaprojects to illustrate the importance of handling ambiguity in order to deliver such projects successfully. The study underscored the need for: integrated project teams expected to come up with innovative solutions in the face of uncertainty and emergence; prototyping and testing new technology offsite prior to introduction on site; and an integrated change control system to deal with progressive elaboration in scope and its consequences. 
To determine the relationship between ambiguity acceptance and project outcomes, Hargen and Park (2013) conducted an online survey of 2 Fortune 100 and 2 Fortune 500 companies, all of which had implemented Six Sigma and used teams as the core deployment tool for improvement projects. Using a combination of Principal Component Analysis, Correlation Analysis and Regression Analysis, the study established a significant positive relationship between ambiguity and both customer and organizational outcomes.

In a study of the antecedents and impacts of ambidexterity in project teams, Liu and Leitner (2012) used an in-depth case study of a complex infrastructure project facing unique challenges and tight budget and schedule to demonstrate the need for simultaneous pursuit of innovation and efficiency in complex engineering projects. They argue that both exploration and exploitation are likely to be needed for complex engineering projects to succeed. The study found that ambidexterity at the project team level is a significant contributor to project performance; the effects of temporal separation and project context on project performance are mediated by the project team's degree of ambidexterity. A key contribution of this study is the characterization of contextual ambidexterity as that which utilizes behavioral and social means of integrating exploration and exploitation. Contextual ambidexterity is achieved through empowering individuals to decide on the time spent on exploration activities or exploitation activities. To achieve contextual ambidexterity, alignment and adaptability of organizational activities and capabilities must be ensured so as to meet changing demands (Birkinshaw, 2004).

In a study to investigate the importance and usefulness of stability (i.e., ability of schedules to absorb emerging disruption) to project outcomes, Swartz (2008) conducted a survey with managers involved in aviation systems development. The study established that stability was perceived to be as important as the more common measures of project performance (time, cost, quality) and that perceptions differed depending on program size, scope (both could be used to explain complexity) and stage of completion and between managers based on their levels of experience and training.

In a study to examine the influence of product requirements ambiguity on new product development task structures, Duimering, Ran, Derbentseva and Poile (2006) used interview data from new product development project managers in a large telecom firm to show that knowledge of how the task structures evolve (emergence) can lead to improved strategies for managing projects with ambiguous requirements. These strategies include decomposition of project tasks to reduce interdependence among tasks and flexible adaptation of the task structures. The study also underscores the role of communication, coordination, knowledge and problem solving in resolving ambiguity.

From the foregoing, it is clear that ambiguity plays a major role in success of projects. The direction of the relationship of ambiguity and success is not apparent as there are instances when it leads to negative consequences and others when it leads to positive consequences, depending on how it is handled. It is on this basis that this study sought to test a non-directional hypothesis that:

$\mathbf{H}_{\mathbf{A}}:$ Ambiguity has significant influence on success of public infrastructural megaprojects.

The relationship is shown below:

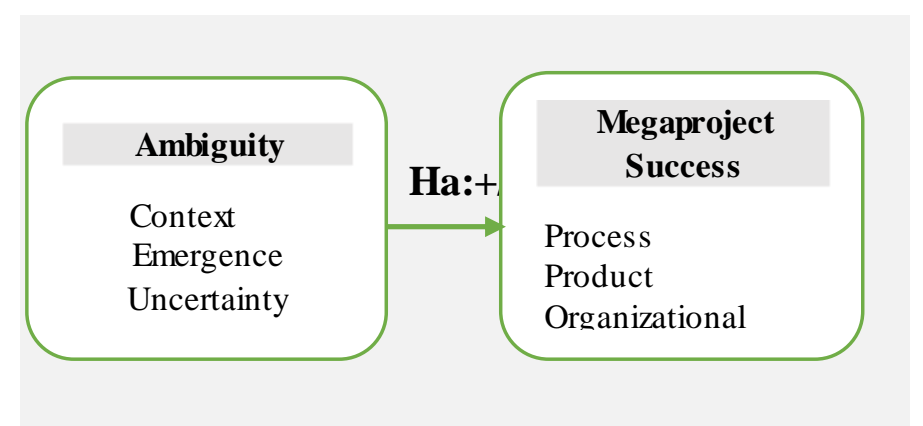

Figure 1: Research Model

\section{Methodology}

\subsection{Research Design}

This study was operationalized through exploratory, descriptive and explanatory research goals based on Neuman (2003) classification of research goals. To achieve these goals, a post-positivist philosophy emphasizing virtual constructionist ontology (Gauthier \& Ika, 2012) was assumed. The choice of this philosophical perspective was guided by the social world of complex megaprojects. In this social world, megaproject management is neither a practice nor a tool (as is the case with projects implemented in the modern social world) but a rallying rhetoric in a context of power play, domination and control (Gauthier \& Ika, 2012).

The study was designed to be mixed-method research combining both quantitative and qualitative strategies (Burch \& Carolyn, 2016). The mixed- 
method research provides an epistemological paradigm that occupies the conceptual space between positivism and interpretivism (Tashakkori \& Creswell, 2007), the main epistemologies on which the virtual constructionist ontology thrives. To generate data for this study, a cross-sectional survey design was used. This design entails the collection of data (predominantly by questionnaire or structured interview) on usually quite a lot more than one case and at a single point in time in order to collect a body of quantitative or quantifiable data in connection with two or more variables, which are then examined to detect patterns of association (Bryman \& Bell, 2007).

\subsection{Target Population}

This study had as its primary population public sector infrastructural megaprojects implemented by the government of Kenya since 2005. Given the continual reorganizations within government and the several projects implemented by the government, it was unlikely that project records and managers for earlier projects could be traced with ease. Following Flyvbjerg (2014), the minimum budget for megaprojects included in this study was approximately Ksh. 1 billion. Managers, team members, sponsors and key stakeholders of these projects constituted the population of respondents from whom data was collected.

The rationale for selecting infrastructure among other foundations of national transformation was based on its huge actual and projected expenditure in comparison to other sectors. Specifically, in the Government of Kenya (2013) Second Medium Term Plan, infrastructure was allocated over Ksh. 7.5 trillion with the second highest allocation of Ksh. 2.5 trillion going to the Information, Communication and Technology sector.

\subsection{Sampling Frame and Sample}

The sampling frame of this study comprised a listing of completed public sector infrastructural megaprojects implemented in Kenya since 2005 with a minimum budget of approximately Ksh. 1 billion. The list of these projects was obtained from the Vision 2030 Secretariat and counterchecked with key informants from government parastatals. A total of 31 such projects was identified. Given the number of completed infrastructural megaprojects for the period under study as described by the sample frame, a census survey was found to be appropriate. Generally, when a sample frame is known, it can also be construed to mean that the population is known. In this case, collecting data on each member of the population becomes possible.

\subsection{Instruments}

The fieldwork for this study utilized two interlinked questionnaires namely, the Complexity Assessment Questionnaire, (CAQ) and the Project Success Questionnaire (PSQ). The CAQ was constructed based on the Practice Standard for Navigating Complexity (PMI, 2014) while the PSQ was developed based on Shenhar and Dvir (2004) and McLeod et al. (2012). Questionnaire survey is hailed to be an efficient data collection mechanism when the researcher knows exactly what is required and how to measure the variables of interest (Neuman, 2003). Both questionnaires utilized a mixture of Likert scale, open ended questions, checklists and probing questions including those soliciting for specific project metrics.

Ambiguity was measured on a 19item scale comprising three constructs namely; context, emergence and uncertainty. The PSQ scale comprised 18 items blending open and closed ended questions on one part and Likert-type questions on the other part. This scale measured success along three constructs namely; process, product and organizational success. The first part involving closed and open ended questions was meant to assess process success while the Likert type questions assessed product and organizational success on a scale of 1 (strongly agree), 2 (agree), 3 (Neither agree nor disagree), 4 (disagree) and 5 (strongly disagree).

\subsection{Pilot Test and Reliability}

The pilot test involved validating data collection instruments and testing the feasibility of the data collection schedule. Through this study, the reliability and dimensionality of the measurement scales were tested to ensure that the items in the scales actually and reliably measured the intended variables. A total of four public infrastructural megaprojects and 16 respondents were surveyed as part of the pilot study. This was well above the " $10 \%$ of the sample projected for the larger parent study" rule (Connelly, 2008). Reliability is concerned with the question of whether the results of a study are repeatable. It is concerned with whether or not the measures that are devised for concepts are consistent (Bryman \& Bell, 2007). Cronbach's (1951) coefficient alpha $(\alpha)$ is commonly used to measure the reliability of the 
scales for Likert-scaled sub-items (Spector, 1992). This is because the underlying assumption of the Likert scale is that it represents an underlying continuous latent scale, although the observations are ordinal (Likert, 1931), and a high score of Cronbach's coefficient alpha means high reliability, stability and accuracy (Papadopoulos, Ojiako, Chipulu \& Lee, 2012). If the sub-items have high agreement and are highly correlated then $\alpha$ will be close to 1. Hair, Babin, Money and Samouel (2003) asserted that an alpha coefficient between 0.8 and 0.9 shows very good strength of association. When $\alpha$ is $\geq 0.7$, the scale is generally reliable (Nunnally, 1978). Following this rule, both instruments were found to be reliable with the Ambiguity scale recording a Cronbach's alpha of 0.837 while the overall internal reliability of the success scale was 0.889 .

\subsection{Data Analysis}

To aid data processing and analysis, this study utilized the Statistical Package for Social Sciences (SPSS) version 20, Microsoft Access 2010 and Microsoft Excel 2010. The original database was created in MS Access (due to its versatility) and then transferred to SPSS for ease of analysis. MS Excel was used to complement SPSS in navigating through data sets during analysis. The SPSS software was chosen for its analytical superiority, availability and ability to handle large amounts of data.

Descriptive statistics for quantitative data analysis were derived using frequencies and percentages, measures of central tendency (mainly the mean), measures of dispersion (mainly standard deviation coefficient of variation, skewness and kurtosis) and Earned Value measures (mainly Cost Performance Index, CPI and Schedule Performance Index, SPI). Inferential statistics were derived using regression and correlation analysis. The overall model for this study assumed the form of a simple linear regression model and was specified as:

$\overline{P S}_{i}=\beta_{1}+\beta_{2} A M_{i}+\mu$

where $\mu_{i}$ the stochastic term and $\beta 2$ is the slope of the regression-change in the coefficient of project success as a result of a unit change in ambiguity score. $\beta_{1}$ is the intercept-the coefficient of project success when there is no ambiguity. The regression coefficients were extracted using Ordinary Least Squares (OLS) method and tested for significance at the 95 percent confidence level using two-tailed $t$ test based on the hypothesis that: $H_{0}: b_{i}=0$; $H_{A}: b_{i} \neq 0$; where $b_{i}$ are the values of individual betas in the estimated regression equation. The significance of the overall model was tested using multiple coefficient of determination $\left(R^{2}\right)$ and the $F$ test. Qualitative data was analyzed using a combination of expert judgment, scenario mapping, retrospective sense-making and critical thinking

\section{Research Findings and Discussion}

\subsection{Introduction}

A total of 27 completed infrastructural megaprojects were studied as part of this research. This represented a return and response rate of $87.1 \%$. Of these projects, 2 (7.4\%) were from Kenya Ports Authority, $2(7.4 \%)$ were from Kenya Pipeline Company, 6 (22.2\%) were from Kenya Airports Authority, 3 (11.1\%) were from Kenya Power and Lighting Company, 1 (3.7\%) was from Kenya Electricity Generating Company, 5 (18.5\%) were from Kenya Urban Roads Authority, 1 (3.7\%) was from Kenya Civil Aviation Authority, 1 (3.7\%) was from Geothermal Development Company, with the remaining $6(22.2 \%)$ coming from Kenya National Highways Authority.

The projects surveyed had a budget at appraisal ranging from approximately Ksh. 1 Billion to Ksh. 327 Billion with 8 of these projects $(29.6 \%)$ having a budget at appraisal of over Ksh. 10 Billion. The scheduled duration for these projects ranged from 4 months to 72 months with most projects having a scheduled duration of above 20 months. The project locations were spread across several counties in Kenya. All the projects were turnkey, involving a variation of Engineer-Procure-Construct (EPC) and Design-Build-Transfer (DBT) delivery arrangements.

\subsection{Findings}

\subsubsection{Project Context}

Ambiguity due to project context was assessed using a checklist that contained several statements regarding various project contractual arrangements and risk handling. The respondents were required to choose all the statements in the checklist that applied to their individual projects. The results showed that of the 27 projects surveyed, 20 projects $(74.1 \%)$ utilized Fixed Price (FP) Contracts with $9(45 \%)$ of these utilizing a Firm Fixed Price/Lump sum (FFP) contract and 11 projects (55\%) utilizing Fixed Price with Economic Price Adjustment (FPEA) contract. One project (3.7\%) utilized a Cost Plus Fixed/Percentage Fee (CPFF/PF)contract while 6 projects $(22.2 \%)$ utilized some form of Cost 
Contracts that involved re-measurement and admeasurement based on initial estimates and Bill of Quantities respectively. Table 1 presents the mean performance statistics of the megaprojects studied based on their contract types.

Table 1: Project Success by Contract Types

$\begin{array}{lcccc}\begin{array}{l}\text { Contract } \\ \text { Type }\end{array} & \begin{array}{c}\text { No. of } \\ \text { Project } \\ \text { S }\end{array} & \begin{array}{c}\text { Mean } \\ \text { Succes }\end{array} & \begin{array}{c}\text { STDE } \\ \text { V }\end{array} & \text { CV } \\ \text { FP-EPA } & 11 & 4.86 & 0.79 & 0.16 \\ \text { FFP } & 9 & 4.3 & 1.01 & 0.24 \\ \text { Remeasurabl } & 6 & 5.11 & 0.60 & \\ \text { e } & & & & 0.13 \\ \text { CPF/PF } & 1 & 5.4 & - & -\end{array}$

The results showed that with the exception of the 1 project that utilized a CPF/PF contract, the projects that utilized cost contracts involving re-/admeasurement had the highest mean success score at 5.11 points out of the possible 6.00 . These projects also recorded the lowest relative variability $(\mathrm{CV}=0.1174)$ in the individual mean success scores. Using the $\mathrm{CV}$ values as measures of riskiness in project success, projects using re-/ad-measurable contracts had less risk followed by those utilizing FP-EPA. The projects utilizing FFP recorded the highest risk in mean success.

Since contractual arrangements are usually a means of allocating cost and schedule risks, this study established that of the 11 megaprojects that utilized FPEA contracts, $6(54.5 \%)$ recorded cost overrun while $8(72.7 \%)$ experienced schedule slippage. Of the 9 projects that utilized FFP contracts, $4(44.4 \%)$ experience cost overruns while $8(88.9 \%)$ experienced schedule delay. Of the 6 projects that utilized re-/ad-measurable contracts, 4 $(66.7 \%)$ were delivered over budget with $5(83.3 \%)$ being delivered behind schedule. This study noted that for projects utilizing FFP contracts, project scope ended up being narrowed to fit into the budget. The $\mathrm{CPF} / \mathrm{PF}$ contract project was delivered on budget but behind schedule. Table 2 summarizes this information.

Table 2: Project Efficiency by Contract Type

\begin{tabular}{lcccc}
$\begin{array}{l}\text { Contract } \\
\text { Type }\end{array}$ & \multicolumn{4}{c}{ Percentage of Projects Delivered } \\
& With: \\
& $C P I \geq 1$ & $C P I$ & $S P I \geq 1$ & $S P I$ \\
& & $<1$ & & $<1$ \\
FP-EPA & $45.5 \%$ & $54.5 \%$ & $27.3 \%$ & $72.7 \%$
\end{tabular}

$\begin{array}{lcccc}\text { FFP } & 55.6 \% & 44.4 \% & 11.1 \% & 88.9 \% \\ \text { Remeasurable } & 33.3 \% & 66.7 \% & 16.7 \% & 83.3 \% \\ \text { CPF/PF } & 100 \% & - & - & 100 \%\end{array}$

Barring the results of the project utilizing $\mathrm{CPF} / \mathrm{PF}$, the results showed that projects utilizing FFP contracts recorded the highest cost performance $(55.6 \%)$ but also recorded the lowest schedule performance $(88.9 \%)$. Projects that utilized FP-EPA contracts exhibited the second highest cost performance $(45.5 \%)$ but also the third lowest schedule performance (after $83.3 \%$ from re-/admeasurable contract projects).

In $13(48.1 \%)$ of the surveyed projects the risk of schedule delay and cost overrun was contractually shared between the client and contractor. Of these projects, 3 (11.1\%) were delivered both on budget and on schedule, 5 $(18.5 \%)$ were delivered on budget but behind schedule with the remaining $5(18.5 \%)$ delivered both with cost overrun and schedule delay. In 3 projects $(11.1 \%)$ the client assumed full responsibility for all the risks and insured against schedule delay and cost overrun. Of these, 1 (3.7\%) was delivered within budget and ahead of schedule, $1(3.7 \%)$ was delivered within budget but behind schedule with the remaining 1 (3.7\%) project delivered over budget but within schedule.

In 8 projects $(29.6 \%)$ the contractor assumed full responsibility for all the risks and provided guarantees. Of these projects, 3 (11.1\%) were delivered on budget, while none was delivered on schedule. In 3 projects (11.1\%) FIDIC conditions were used and schedule and cost risks were handled as they occurred. Of these projects, $1(3.7 \%)$ was delivered within budget while none was delivered within schedule. In summary, these results show that of the 24 megaprojects that either transferred risk to the contractor or shared it between the client and the contractor, 13 megaprojects $(54.2 \%)$ were delivered on budget while only 3 megaprojects $(12.5 \%)$ were delivered within schedule.

Of the 3 megaprojects where the client assumed full responsibility for cost and schedule risk, $2(66.7 \%)$ of these met both cost and schedule objectives. Generally, the results show that megaprojects that either transferred risk to the contractor or shared risk between the contractor and client had better cost performance but poor schedule performance.

\subsubsection{Emergence}

Project ambiguity arising from emergence was measured using a 6-item Likert type scale largely 
centred on assessing project stability. The responses on each item were rated on a 5-point mutually exclusive scale where a rating of 1 denoted a "strongly agree" response, 2 denoted "agree" response, 3 denoted "somewhat agree" response, 4 denoted "disagree" response, while 5 denoted a "strongly disagree" response. A choice of either 1 (strongly agree) or 2 (agree) implied low ambiguity while a choice of either 4 (disagree) or 5 (strongly disagree) implied high ambiguity. A choice of 3 (somewhat disagree) implied a neutral and borderline response which did not communicate much on the complexity of projects studied. As such, this neutral response was dropped from further analysis.

The results indicated that a total of $48.1 \%$ of the respondents agreed that assumptions, metrics and constraints remained stable throughout the life of their projects while $22.2 \%$ of the respondents disagreed with this statement. A total of $40.7 \%$ of the respondents agreed that the stakeholder requirements remained stable throughout their project life while $29.6 \%$ disagreed. On average, $55.5 \%$ of the respondents agreed that their projects were implemented in a politically and environmentally stable context with $18.5 \%$ of the respondents disagreeing. An aggregate of $81.5 \%$ of the respondents confirmed that the actual rate and type or propensity for change within their projects was manageable while $3.7 \%$ disagreed. In $70.3 \%$ of the projects surveyed, the respondents agreed that there was a documented change control system with identifiable change authority. However, in $14.8 \%$ of the projects, this was not the case. The results further indicated that contractual arrangements included incentives for the parties to assume responsibility for emerging project risks in only $7.4 \%$ of the projects. Table 4.20 summarizes these responses.

The cost and schedule performance results were mapped onto the responses with one cluster containing projects that either strongly agreed or agreed with the statements and the other containing those that disagreed or strongly disagreed. The results showed that for the projects in which assumptions, metrics and constraints remained stable through the life of the project, $53.8 \%$ were delivered on budget while $15.4 \%$ of those projects were delivered on schedule. Where assumptions, metrics and constraints did not remain stable throughout the life of the project, the results indicate that $66.7 \%$ of such projects were delivered within budget with only $16.7 \%$ of them being delivered within schedule.
Of the 11 projects in which stakeholder requirements remained stable throughout their life cycle, $54.5 \%$ were delivered within budget while $18.2 \%$ of those projects were delivered within schedule. For the projects in which stakeholder requirements did not remain stable throughout their life cycle, $50 \%$ were delivered within budget with only $12.5 \%$ of those projects being delivered within schedule. Projects which were conducted in a politically and environmentally stable context recorded a $46.7 \%$ chance of delivery within budget but only $20 \%$ of those projects were delivered within schedule.

Of the projects which were conducted in a politically and environmentally unstable context, $40 \%$ were delivered within budget with none of those projects being delivered within schedule. For the projects in which the actual rate and type or propensity for change was not manageable, $45.5 \%$ were delivered on budget while only $13.6 \%$ were delivered on schedule. Where the actual rate and type or propensity for change was not manageable, the project was delivered with both cost overrun and schedule delay. For the projects that had a documented change control system with identifiable change authority, $57.9 \%$ were delivered within budget while $21.1 \%$ were delivered within schedule.

The results further indicated that of the projects in which there was no documented change control system with identifiable change authority, $50 \%$ were delivered within budget but none of them was delivered within schedule. None of the projects surveyed utilized contractual arrangements that included incentives for the parties to assume responsibility for emerging project risks. However, for the projects in which contractual arrangements did not include incentives for the parties to assume responsibility for emerging project risks, $48.2 \%$ were delivered within budget with $18.5 \%$ being delivered within schedule.

\subsubsection{Uncertainty}

Ambiguity arising from uncertainty was measured using an 11-item Likert-type scale. The responses on each item were rated on a 5-point mutually exclusive scale where a rating of 1 denoted a "strongly agree" response, 2 denoted "agree" response, 3 denoted "somewhat agree" response, 4 denoted "disagree" response, while 5 denoted a "strongly disagree" response. A choice of either 1 (strongly agree) or 2 (agree) implied low ambiguity while a choice of either 4 (disagree) or 5 (strongly disagree) implied high ambiguity. A choice of 3 (somewhat disagree) implied a neutral and 
borderline response which did not communicate much on the complexity of projects studied. As such, this neutral response was dropped from further analysis.

The results showed that $40.7 \%$ of the respondents agreed that their projects were conducted over a relatively short period of time with a manageable number of stakeholder changes, while an equal proportion of respondents disagreed. A total of $77.7 \%$ of the projects surveyed indicated that the requirements, scope and objectives were clearly developed while $7.4 \%$ disagreed. An aggregate $74 \%$ of the respondents confirmed that the success criteria for their projects were defined, documented and agreed upon by the stakeholders while $7.4 \%$ of the respondents disagreed.

Funding in $63 \%$ of the projects surveyed came from a single source or sponsor. In $33.3 \%$ of the projects, funding came from multiple sources. A total of $66.7 \%$ of the respondents indicated that their organizations had implemented similar projects before while $29.6 \%$ had not. In $81.5 \%$ of the projects, there were a manageable number of issues, risks and uncertainties but this was not the case in $11.1 \%$ of the projects. It was indicated in $66.6 \%$ of the projects that suppliers were able to meet their commitments to the projects while in $7.4 \%$ of the projects, suppliers did not meet their commitments.

In $71.3 \%$ of the projects, the client was prepared in advance to accept and sign off deliverables but this was not the case in $11.1 \%$ of the projects. In slightly over $85 \%$ of the projects surveyed, project documents and files were kept current in an accessible location by the team but this was not the case in $3.7 \%$ of the projects. Finally, $74 \%$ of the respondents indicated that their projects had a manageable number of critical paths while $3.7 \%$ did not agree. Table 4.22 summarizes these responses.

To check the relationship between uncertainty and project success, the cost and schedule performance results for the projects were mapped onto the responses. The results indicated that $54.5 \%$ of the projects in which respondents agreed that the project was conducted over a relatively short period of time with a manageable number of stakeholder changes were delivered within budget with $27.3 \%$ of those projects being delivered within schedule. Of the 11 projects in which the respondents disagreed with this statement, $63.6 \%$ were delivered within budget while only $9.1 \%$ of those projects were delivered within

schedule.

Of the projects in which requirements, scope and objectives were clearly developed, $54.5 \%$ were delivered within budget with only $22.7 \%$ of those projects being delivered within schedule. Both the two projects in which the project requirements, scope and objectives were not clearly defined, were delivered within budget but only 1 was delivered on schedule. For the projects in which the success criteria was defined, documented and agreed upon by the stakeholders, $55 \%$ were delivered within budget while $25 \%$ were delivered within schedule. Both the projects in which the success criteria was not defined, documented and agreed upon by the stakeholders, were delivered on budget with none being delivered on schedule.

An aggregate $46.7 \%$ of the projects whose funding was obtained from a single source or sponsor were delivered within budget with $26.7 \%$ of those projects being delivered within schedule. Where project funding came from multiple sources or sponsors, $55.6 \%$ were delivered within budget with none being delivered on schedule. For projects which had not been undertaken by the organization before, the chance of delivery within budget was $44.4 \%$ while that of delivery within schedule was $22.2 \%$. Where that type of project was being delivered by the organization for the first time, the chance of delivery within budget went down to $37.5 \%$ while that of delivery on schedule dropped to 12.5\%. In circumstances where the project had a manageable number of issues, risks and uncertainties, delivery within budget was recorded in $45.5 \%$ of the projects while delivery within schedule was recorded in only $13.6 \%$ of the projects. Where there were unmanageable number of issues, risks and uncertainties, cost delivery went down to $33.3 \%$ while schedule delivery slipped to zero. In projects where suppliers were able to meet commitments, $44.4 \%$ were delivered within budget and $16.7 \%$ were delivered within schedule. For the 2 projects in which suppliers could not meet their commitments, one was delivered on budget while both were delivered behind schedule. Of the 7 projects that were delivered to the committed deadlines, only 1 was delivered within budget, none was delivered within schedule. Where the projects did not deliver to the committed deadlines, $25 \%$ were delivered within budget but none was delivered within schedule.

In circumstances where the client was prepared in advance to accept and sign off deliverables, the chance of delivery within schedule was $52.6 \%$ and that of delivery within budget was $26.3 \%$. These went down to $33.3 \%$ and $0 \%$ in circumstances where the client was not prepared in advance to accept and sign off deliverables. The 
results also indicate that of the 26 projects in which project documents and files were kept current in an accessible location by the team, $43.5 \%$ of those

\begin{tabular}{|l|l|l|l|}
\hline $\begin{array}{l}\text { Project } \\
\text { Success } \\
\text { ce }\end{array}$ & $\begin{array}{l}\text { Emergen } \\
\text { nty }\end{array}$ & $\begin{array}{l}\text { Ambigui } \\
\text { ty } \\
\text { score }\end{array}$ \\
\hline $\begin{array}{l}\text { Process } \\
\text { Success }\end{array}$ & $-.495^{* *}$ & $-.706^{* *}$ & $-.687^{* *}$ \\
\hline $\begin{array}{l}\text { Product } \\
\text { Success }\end{array}$ & -.139 & -.236 & -.214 \\
\hline $\begin{array}{l}\text { Organizati } \\
\text { onal } \\
\text { Success }\end{array}$ & .133 & -.101 & .035 \\
\hline $\begin{array}{l}\text { Composite } \\
\text { Success }\end{array}$ & -.353 & $-.641^{* *}$ & $-.561^{* *}$ \\
\hline $\begin{array}{l}* \text { Correlation is significant at the } 0.05 \text { level } \\
\text { (2-tailed). }\end{array}$ \\
\hline $\begin{array}{l}\text { **. Correlation is significant at the } 0.01 \text { level } \\
\text { (2-tailed). }\end{array}$ \\
\hline
\end{tabular}

projects were delivered within budget with $17.4 \%$ of those projects being delivered within schedule. The project in which this was not the case was delivered within budget but behind schedule. Of the 20 projects in which there were a manageable number of critical paths in the project, delivery within budget was recorded in $40 \%$ of the projects while delivery within schedule was recorded in $25 \%$ of the projects. The project in which there were many critical paths was delivered within budget but behind schedule.

\subsubsection{Hypothesis Testing}

In order to test the hypothesis that ambiguity has a significant influence on success of public infrastructural megaprojects, the constructs of ambiguity were scored to determine their complexity scores. The context construct was used to explain the constructs of emergence and

Causal relationship between ambiguity and megaproject success was tested using OLS linear regression at the $95 \%$ confidence level. The results indicated that there was no serial correlation in the data used to conduct regression analysis given a Durbin-Watson statistic value less than 2. Data was also checked for collinearity using the Tolerance and VIF statistics. The results indicated that the VIF was much lower than the cut-off value of 4 which is used as the threshold to indicate multicollinearity particularly in small samples (O'Brien, 2007). The problem of heteroscedasticity was checked using residual statistics plotted on a scatter diagram. The uncertainty and was therefore not scored to determine the overall ambiguity score. The results show that the emergence construct had a mean score of 2.49 with a standard deviation of 0.66 while the uncertainty construct recorded a mean score of 2.17 with a standard deviation of 0.52 . The weighted ambiguity score had a mean of 2.33 with a standard deviation of 0.52 . The results indicated that the emergence scores had the highest relative variability $(\mathrm{CV}=0.26)$ compared to that of uncertainty $(\mathrm{CV}=0.24)$ and the weighted score $(\mathrm{CV}=0.22)$. With the coefficients of skewness and kurtosis being within the acceptable range of -1 to +1 for skewness and -2.2 to +2.2 for kurtosis (Sposito, Hand, \& Skarpness, 1983), the data was approximately normal and could therefore be used to conduct parametric tests such as correlation and regression.

Ambiguity scores were first correlated with those of project success to determine if they had any association. The results showed that at $99 \%$ confidence level, emergence had a significant negative correlation with process success ( $\mathrm{r}=-0.495)$ and uncertainty had a strong significant negative correlation with process success $(\mathrm{r}=-0.706)$. Overall, the results showed that ambiguity had significant negative correlation with process success (CV=0.687). The results indicated that both emergence and uncertainty had no relationship with product and organizational success, but uncertainty had a 0.641 correlation with the overall project success. The correlations are shown in Table 3.

Table 3: Correlation between Ambiguity and Project

Success

results indicated that almost all the residuals had a mean of 0.000 and approximately equally spread around their mean implying that the data was roughly homoscedastic and was therefore good for OLS regression analysis. The results indicated that the overall model had a $31.5 \%$ predictive power $\left(R^{2}=0.315\right)$. ANOVA results showed that the overall model was significant with $F_{(1,25)}=11.501$ and $P$ Value $<\frac{\alpha}{2}$. The regression equation is presented below:

$$
\begin{gathered}
P S_{i}=6.461-0.743 A M_{i} \\
s\left(\hat{b_{i}}\right)=(0.522) \quad(0.219) \\
t=(12.368) \quad(-3.392) \\
R^{2}=0.315
\end{gathered}
$$


Where $s\left(\hat{b}_{i}\right)$ is the standard error of beta estimate.

The results show that at $95 \%$ confidence level, the $s\left(\hat{b}_{i}\right)<\left(\frac{\hat{b_{i}}}{2}\right)$ for both the intercept and the slope of

the equation. Thus, following Koutsoyiannis (1992), the null hypothesis that $b_{0}=b_{1}=0$ was rejected and a conclusion made that the betas were significant. The results showed that the slope of Ambiguity was significant, implying that a one unit increase in ambiguity reduced project success score by 0.743 . Thus, the research hypothesis that ambiguity has a significant influence on success of public infrastructural megaprojects was accepted.

\section{Discussion}

It is generally recognized in normative literature that the FFP is the most commonly used contract type (PMI, 2013c). However, this study established that most infrastructural megaprojects utilized FPEPA and the FFP was utilized by just one third of the projects surveyed. Given the sample size of this study, it may be difficult to draw a conclusion against the postulation of normative literature. The use of FP-EPA contractual arrangements is backed by the long term nature of the projects studied with the implementation of some spanning up to 6 years. With such longer implementation periods, it is likely that factors outside the control of the client or contractor, such as inflation and currency fluctuation, may adversely affect cost performance.

The use of Fixed Price contracts is usually a tactic of transferring the risk of cost overrun to the contractor. In the case of FFP contracts, the entire risk of cost overrun is actually transferred from the client to the contractor. In such cases, the contractors are usually careful not to eat into their profit margins. The results of this study agree with this practice given that a larger proportion of projects that utilized FFP contracts recorded the highest cost performance. This was followed by projects that utilized FP-EPA, which is a variation of FP contracts. Despite having recorded superior cost performance, projects that utilized FFP recorded the highest schedule slippage. This could mean that utilizing FFP contracts could be a zero sum game-since project management success must take into account both cost and schedule performance. It is noted that projects whose contracts included late delivery penalties actually delivered on schedule. This means that the use of
FFP should be adjusted to include late delivery penalties if the objectives of both cost and schedule are to be achieved simultaneously.

The results indicated that none of the projects utilized contractual arrangements with incentives for accelerated cost or schedule delivery. Such pain/gain contracts would include Fixed Price Incentive Fee, Cost-Plus Incentive Fee or Cost-Plus Award Fee. The use of these types of contracts incentivizes the contractor for superior delivery of the pre-agreed performance metrics such as schedule and cost performance (PMI, 2013). As such, using these types of contracts is strongly associated with superior project performance (Brady \& Davis, 2014) since the parties involved in the project may prefer different actions because of their different risk preferences (Eisenhardt, 1989). Thus, the pain/gain contractual arrangements can be critical in solving the agency problem that characterizes most employer-contractor relationships (Jensen \& Meckling, 1976) on projects.

It is argued that transferring risk to the contractor (as in the use of Fixed Price contracts) offers no real protection for the client because the client is always accountable for cost, time, quality and safety (Brady \& Davis, 2014). The results of this study agree with this argument given that 2 out of the 3 projects in which the client assumed full responsibility for risk of cost overrun and schedule delay met their cost and schedule objectives. Thus, even though numbers are still small, the findings of this study could be pointing to the fact that behavior-oriented contracts lead to better results than outcome-based contracts.

The results of this study seem to agree with the postulation of normative literature that emergence can have both positive and negative effect on project outcomes. (PMI, 2014). Emergence may enhance the ability of a project to innovate which in turn could improve project delivery capability. As an illustration, projects in which assumptions, metrics and constraints did not remain stable throughout their life recorded much better cost and schedule performance compared to those in which assumptions, metrics and constraints remained stable. The implication of this is that contractual arrangements in projects should ensure collaborative efforts with appropriate incentives to encourage the parties to solve problems that emerge as a result of progress elaboration and during execution (Brady \& Davis, 2014).

Stability of stakeholder requirements is a key aspect of complexity that affects the delivery 
capability of a project since emergence in stakeholder requirements implies emergence in scope. As the findings of this study attest, emergence in stakeholder requirements throughout the project's life cycle could lead to reduced cost and schedule performance thereby dimming chances of project management success.

Likewise, stability in the political and physical environment of a project could affect project delivery capability. In this study, instability in the political and physical environment adversely affected chances of delivery within budget and schedule. This is plausible particularly given that public infrastructural projects are implemented in delivery of a "political manifesto" and so instability in the political system inevitably affects project management success.

As noted by Swartz (2008), emergence can disrupt a project schedule, and the ability of the schedule to absorb that disruption is critical for the delivery of project outcomes. In situations where the actual rate and type or propensity for change is not manageable, as is the case in complex infrastructural megaprojects, the apparent schedule disruption may also disrupt cost performance. Indeed, the results of this study attest to this-where the actual rate and type or propensity for change was not manageable, cost and schedule delivery slipped to zero. In most cases where the project context was not stable, schedule delivery was adversely affected.

Change management is known to create a superior culture that supports open communication, trust and cooperation (Kerzner, 2009) among various stakeholders on the project. It allows for documented changes within the project to be considered in an integrated fashion while reducing project risk (PMI, 2013c). A well-documented change control system helps to identify, assess and control any potential and approved changes to the project baselines (Axelos, 2017) in order to avoid scope creep. In support of this, the results of this study show that projects that had a documented change control system with identifiable change authority returned a higher probability of delivery within budget and schedule.

Whereas none of the projects surveyed utilized contractual arrangements that included incentives for the parties to assume responsibility for emerging project risks, positive literature suggests that behavior-based contracts could return better project success results than outcome-based contracts. Such contracts enhance ambidexterity (simultaneous pursuit of efficiency and innovation) on projects, which in effect has significant effect on project performance (Liu \& Leitner, 2012). This is supported in a study to compare the complexity of two successful projects by Brady and Davis (2014) who showed that the use of collaborative pain/gain contracts can indeed enhance project success.

Empirical research shows that the longer the duration of the project the larger its cost overrun (Flyvbjerg et al., 2004). However, based on the findings of this study, longer schedule duration is associated with increased delivery of projects under budget. This finding appears to be in line with the thinking of economic theory that uncertainties are necessary conditions for the existence of opportunities and that without uncertainty entrepreneurial profits would be impossible (Knight, 1948). What is apparent from the findings of this study is that longer schedule duration is associated with reduced delivery within schedule.

Clear requirements documentation and scope definition are critical prerequisites for designing quality scope baselines. This also involves developing and documenting clear success criteria that is agreed upon by the stakeholders. Complexity arising from uncertainty affects the stability of project baselines and of the decisions made. The results of this study showed that high uncertainty has more negative effect on schedule performance than on cost performance. Chances of delivery over budget and behind schedule were high where the client was not prepared in advance to accept and sign off deliverables, implying that benefits realization planning is important for project success.

The results also showed that delivery over budget and behind schedule was equally high where the project had a large number of issues, risks and uncertainties. The implication of this is that change and risk management planning are critical to avoid firefighting whenever the vagaries of uncertainty hit a project. The Practice Guide on Navigating Complexity (PMI, 2014) recognizes that adequate risk and change management procedures should be in place to enable proper actions during the times of uncertainty, and risk sharing and collaboration are key strategies to handle uncertainty. This study found that chances of delivery over budget and behind schedule are also high in circumstances where that type of project had not been undertaken by the organization before. This confirms that the principle of learning from experience could lead to better project outcomes (Axelos, 2017).

The results of this study indicate that ambiguity has only significant relationship with 
process success. The implication of this is that accepting and dealing with ambiguity should be a key aspect of project management. Hagen and Park (2013) assert that acceptance of ambiguity is a key trait that differentiates between effective and ineffective leaders. The results of this study also indicate a significant positive relationship between emergence and uncertainty $(\mathrm{r}=.454)$. The implication of this is that there is an overlap between these constructs and distinguishing their independent effects on project outcomes can be difficult.

It is recognized in normative literature that ambiguity can have either positive or negative effect on project outcomes (PMI, 2014). In a study on the effects of ambiguity on project task structure in new product development, Duimering, Ran, Derbentseva and Poile (2006) concluded that knowledge of how the task structures evolve (emergence) can lead to improved strategies for managing projects with ambiguous requirements. However, the findings of this study only established that ambiguity leads to negative project outcomes.

\section{Conclusions and Recommendation}

Ambiguity had significant negative influence on process and overall project success but had no significant relationship with product or organizational success. Thus, as the infrastructural megaproject's context becomes ambiguous, its success is negatively impacted. Both uncertainty and emergence appeared to negatively affect schedule delivery more than cost delivery. This is explained by the contractual context in which these projects were implemented. Infrastructural

megaprojects majorly utilized FFP and FP-EPA contracts. Even though usage of these contract types led to increased chances of delivery within budget, they carried with them an inherent risk of delivery behind schedule. However, inclusion of late delivery penalties in these contracts helped remedy the risk of schedule slippage. Projects in which the client assumed responsibility for cost and schedule risk had higher chances of meeting both cost and schedule objectives when compared to those in which risk was either transferred to a third party or shared contractually. Transferring or sharing project risk increased chances of achieving the cost objective but greatly reduced chances of meeting the schedule objective. The results of this study point to the fact that the effects of ambiguitywhether from the project's context, emergence or uncertainty, can be managed contractually.

Neither the usage of outcome-based nor behavior-based contracts in isolation can solve the negative effect of ambiguity on success of public infrastructural megaprojects. We recommend that the design of these projects utilizes hybrid contracts based on complexity science and blending both outcome and behavior based contracts. Such contracts should ensure that the contractors are able to act in the best interest of their clients and that the clients have access to Project Management Information Systems (PMIS) capable of supplying them with information required to verify the behavior of contractors. Such PMIS could include Earned Value Management Systems (EVMS) or Risk Management System (RMS) to enable identification of management of Early Warning Signs (EWS).

\section{References}

[1] Atkinson, R. (1999). Project management: Cost, time and quality, two best guesses and a phenomenon, it is time to accept other success criteria. International Journal of Project Management, 17(6), 337-342.

[2] Axelos Limited. (2017). Managing Successful Projects with PRINCE2 ${ }^{\circledR}{ }^{\circledR} 6^{\text {th }}$ ed.). United Kingdom: TSO, ISBN: 9780113315338.

[3] Baccarini, D. (1999). The logical framework method of defining project success. Project Management Journal, 30(4), 25-32.

[4] Bannermann, P.L. (2008). Defining project success: A multilevel framework. In Proceedings of the PMI Research Conference (pp. 1-14). Newton Square, PA: Project Management Institute.

[5] Brady, T., \& Davies, A. (2014). Managing Structural and Dynamic Complexity: A Tale of Two Projects. Project Management Journal, 45(4), 21-38.

[6] Bruzelius, N., Flyvbjerg, B., Rothengatter, W. (2002). Big decision, big risks. Improving accountability in mega projects. Transport Policy, 9(2), 143-154.

[7] Bryman, A., \& Bell, E. (2007). Business Research Methods (2 ${ }^{\text {nd }}$ ed.). New York, United States: Oxford University Press Inc., p. 55.

[8] Burch, P., \& Carolyn, H. J. (2016). Mixed Methods for Policy Research and Program Evaluation. Thousand Oaks, CA: Sage.

[9] Caldart, A. A., \& Joan, E. R., (2004). Corporate Strategy Revisited: A View from 
Complexity Theory. European Management Review, 1(1).

[10] Collyer, S. (2016). Culture, Communication, and Leadership for Projects in Dynamic Environments. Project Management Journal, 47(6), 111-125.

[11] Connelly, L. M. (2008). Pilot studies. Medsurg Nursing, 17(6), 411-412.

[12] Cooke-Davies, T. (2002). The real success factors on projects. International Journal of Project Management, 20(3), 185-190.

[13] Cooke-Davies, T., Crawford, L., \& Stevens, C. (Eds.). (2011). Aspects of Complexity: Managing projects in a complex world. Pennsylvania, USA: Project Management Institute.

[14] Cronbach, L.J. (1951). Coefficient alpha and the internal structure of tests. Psychometrika, 16(3), 297-334.

[15] de Wit, A. (1988). Measurement of Project success. Project Management Journal, 6(3), 164-170.

[16] Duimering, P.R., Ran, B., Derbentseva, N., \& Poile, C. (2006). The Effects of Ambiguity on Project Task Structure in New Product Development, Knowledge and Process Management, 13(4), 239-251.

[17] Flyvbjerg, B. (2014). What You Should Know About Mega Projects and Why: An Overview. Project Management Journal, 45(2), 6-17.

[18] Flyvbjerg, B., Holm, M.K.S., \& Buhl, S.L. (2004). What causes cost overrun in transport infrastructure projects? Transport Reviews, 24 (1), 3-18.

[19] Gauthier, J-B., \& Ika, L.A. (2012). Foundations of Project Management Research: An Explicit and Six-facet Ontological Framework. Project Management Journal, 43(5), 5-23.

[20] Government of Kenya. (2013). Second Medium Term Plan, 2013-2013. Kenya Vision 2030: Author.

[21] Hagen, M., \& Park, S. (2013). Ambiguity Acceptance as a Function of Project Management: A new Critical Success Factor. Project Management Journal, 44(2), 52-66.

[22] Hair, J.F., Babin, B., Money, A., \& Samouel, P. (2003). The essentials of business research methods. London: Wiley.

[23] Hirschman, A.O. (1995). Development projects observed ( $2^{\text {nd }}$ ed.). Washington, D.C: Brookings Institution.
[24] Hoegl, M., \& Gemuenden, H.G. (2001). Team work quality and the success of innovative projects: A theoretical concept and empirical evidence. Organization Science, 12(4), 435-449.

[25] Ika, L.A. (2009). Project success as a topic in project management journals. Project Management Journal, 40(4), 6-19.

[26] Jensen, M., \& Meckling, W. (1976). Theory of the firm: Managerial behavior, agency costs, and ownership structure. Journal of Financial Economics, 3, 305-360.

[27] Jugdev, K., \& Muller, R. (2005). A retrospective look at our evolving understanding of project success. Project Management Journal, 36(4), 19-31.

[28] Jugdev, K., Thomas, J., \& Delisle, C.L. (2001). Rethinking Project Management: Old truths and new insights. Project Management Journal, 7(1), 36-43.

[29] Kahneman, D., \& Tversky, A. (1979). Intuitive prediction: biases and corrective procedures. In S. Makridakis, \& S. C. Wheelwright (Eds.), Studies in the Management Sciences: Forecasting, 12. North-Holland, Amsterdam, pp.313-27.

[30] Kellert, S. H. (1993). In the Wake of Chaos: Unpredictable Order in Dynamical Systems. University of Chicago Press.

[31] Kerzner, H. (2008), Project Management-A Systems Approach to Planning, Scheduling, and Controlling, $\left(10^{\text {th }}\right.$ ed.). John Wiley \& Sons Inc.

[32] Knight, E. H. (1948). Risk, Uncertainty and Profits $\left(7^{\text {th }}\right.$ ed.). London, England: London School of Economics and Political Science.

[33] Koutsoyiannis, A. (1992). Theory of Econometrics ( $2^{\text {nd }}$ ed.). Hong Kong: Macmillan Education.

[34] Likert, R. (1931). A technique for the measurement of attitudes. Archive of psychology, 22(140), 1-55.

[35] Liu, L., \& Leitner, D. (2012). Simultaneous Pursuit of Innovation and Efficiency in Complex Engineering Projects-A Study of the Antecedents and Impacts of Ambidexterity in Project Teams. Project Management Journal, 43(6), 97-110.

[36] Lorenz, E. N. (1963). Deterministic nonperiodic flow. Journal of the Atmospheric Sciences, 20 (2), 130-141.

[37] Lovallo, D., \& Kahneman, D. (2003). Delusions of success, how optimism 
undermines executives' decisions.Harvard Business Review, 81 (7), 57-63

[38] Lucas, T. (2009). Quantifying complexity. Website.

[39] www.calresco.org/lucas/quantify.htm. March 2015.

[40] Mackie, P. and J. Preston (1998). "Twentyone sources of error and bias in transport project appraisal." Transport Policy, 5, pp 17.

[41] Markus, M.L., \& Mao, J.Y. (2004). Participants in development and implementation- Updating an old tired concept for today's IS contexts. Journal of the Association for Information Systems, 5(11-12), 514-544.

[42] Maylor, H., Vidgen, R., \& Carver, S. (2008). Managerial Complexity in Project based Operations: A grounded model and its implications for practice. Project Management Journal, 39(1), 15-26.

[43] McLeod, L., Doolin, B., \& MacDonell, G. S. (2012). A Perspective-Based Understanding of Project Success. Project Management Journal, 43(5), 68-86.

[44] Meyer, W. G. (2014). The Effect of Optimism Bias on the Decision to Terminate Failing Projects. Project Management Journal, 45(4), 7-20.

[45] Neuman, W.L. (2003). Social research methods: Qualitative and quantitative approaches, $\left(^{\text {th }}\right.$ ed.). Upper Saddle River, NJ: Pearson Education.

[46] Olaniran, O.J., Love, P.E.D., Edwards, D., Olatunji, O.A., \& Mathews, J. (2015). Cost Overruns in Hydrocarbon Megaprojects: A Critical Review and Implications for Research. Project Management Journal, 46(6), 126-138.

[47] Papadopoulos, T., Ojiako, U., Chipulu, M., \& Lee, K. (2012). The Criticality of Risk Factors in Customer Relationship Management Projects. Project Management Journal, 43(1), 65-75.

[48] Project Management Institute. (2013). A Guide to the Project Management Body of Knowledge $\left(5^{\text {th }}\right.$ ed.). Pennsylvania, USA: Author.

[49] Project Management Institute. (2014). Navigating Complexity: A Practice Guide. Pennsylvania, USA: Author.

[50] Remington, K., \& Zolin, R. (2011). Controlling Chaos? The Value of the
Challenges of applying complexity theory to project management. In T. Cooke-Davies, L. Crawford, \& C. Stevens, (Eds.), Aspects of Complexity: Managing Projects in a Complex World, (pp. 115-128).

Pennsylvania, USA: Project Management Institute.

[51] Shenhar, A. J., \& Dvir, D. (2007a).Reinventing project management: the diamond approach to successful growth and innovation. Boston, MA: Harvard Business School Press.

[52] Shenhar, A.J., \& Dvir, D. (2007b). Project management research-The challenge and opportunity. Project Management Journal, 38(2), 93-99.

[53] Shenhar, A.J., Dvir, D., Levy, O., \& Maltz, A.C. (2001). Project success: A multidimensional strategic concept. Long Range Planning, 34(6), 699-725.

[54] Spector, P. (1992). Summated rating scale construction. Thousand Oaks, CA: SAGE.

[55] Sposito, V., Hand, M., \& Skarpness, B. (1983). On the Efficiency of Using the Sample Kurtosis in Selecting Optimal Ipestimators. Communications in Statistics, Simulation and Computation, 12(3), 265-272.

[56] Swartz, S.M. (2008). Managerial Perceptions of Project Stability. Project Management Journal, 39(4), 17-32.

[57] Tashakorri, A., \& Creswell, W.J. (2007). "The New Era of Mixed Methods." Journal of Mixed Methods Research, 1 (1), 3-7.

[58] Waldrop, M.M. (1992). Complexity: The Emerging Science at the Edge of Order and Chaos. New York: Touchstone.

[59] Wateridge, J. (1998). How can IS/IT projects be measured for success? International Journal of Project Management, 16(1), 5963. 